\title{
Online Appendix: Discrimination in Ambient Air Pollution Monitoring?
}

\author{
Corbett Grainger and Andrew Schreiber
}

Here we present the estimates of the linear probability models (LPM) described in the main text. Table 1 shows cross-sectional LPM estimates from 2015. The outcome variable is an indicator for whether that grid cell contains an ambient pollution monitor; the zscore is calculated using the BEHR remote sensing estimates of $\mathrm{NO} 2$; and demographic variables come from the 2007-2011 5-year block group-level American Community Survey. The first column includes all AQS monitors that monitored ozone, and columns (2)-(5) restricts the sample to SLAMS monitors. Robust standard errors are clustered at the air quality management district level.

Table 2 shows estimates of an LPM for new monitor sitings, described in Section III of the text. An observation is at the grid cell-by-year level using the BEHR remote sensing data. The sample consists of county-by-year combinations that received a new ambient pollution monitor. The outcome variable is an indicator for whether that grid cell received a new pollution monitor, and the sample covers the years 2005-2015. The z-score is calculated using BEHR remote sensing estimates; demographic variables come from the 2007-2011 5-year block group-level American Community Survey. The first three columns include all AQS monitors that monitored ozone, and columns (4)-(6) restricts the sample to new SLAMS

monitors. We've suppressed fixed effect parameter estimates. Robust standard errors are clustered at the air quality management district level. 
Table 1: Cross-Sectional LPM Estimates for All Monitor (2015)

\begin{tabular}{|c|c|c|c|c|c|}
\hline & $\begin{array}{c}(1) \\
\text { Monitor Indicator }\end{array}$ & $\begin{array}{c}(2) \\
\text { SLAMS Monitors }\end{array}$ & $\begin{array}{c}(3) \\
\text { SLAMS Monitors }\end{array}$ & $\begin{array}{c}(4) \\
\text { SLAMS Monitors }\end{array}$ & $\begin{array}{c}(5) \\
\text { SLAMS Monitors }\end{array}$ \\
\hline NO2 Zscore & $\begin{array}{l}0.00720^{* * *} \\
(0.00144)\end{array}$ & $\begin{array}{r}0.00634^{* * *} \\
(0.00122)\end{array}$ & $\begin{array}{r}-0.000281 \\
(0.00140)\end{array}$ & $\begin{array}{l}0.0118^{* * *} \\
(0.00342)\end{array}$ & $\begin{array}{l}0.0109^{* * *} \\
(0.00402)\end{array}$ \\
\hline Attain*(NO2 Zscore) & $\begin{array}{c}-0.00508^{* * *} \\
(0.00143)\end{array}$ & $\begin{array}{c}-0.00466^{* * *} \\
(0.00118)\end{array}$ & $\begin{array}{l}0.000815 \\
(0.00133)\end{array}$ & $\begin{array}{c}-0.00989^{* * *} \\
(0.00343)\end{array}$ & $\begin{array}{c}-0.00915^{* *} \\
(0.00400)\end{array}$ \\
\hline Median Household Income & $\begin{array}{r}-0.000117^{* * *} \\
(0.0000276)\end{array}$ & $\begin{array}{r}-0.000112^{* * *} \\
(0.0000248)\end{array}$ & $\begin{array}{c}-0.0000822^{* * *} \\
(0.0000263)\end{array}$ & $\begin{array}{r}-0.000163^{* * *} \\
(0.0000439)\end{array}$ & $\begin{array}{r}-0.000108^{* * *} \\
(0.0000246)\end{array}$ \\
\hline Poverty Rate & $\begin{array}{l}0.000254^{* * *} \\
(0.0000638)\end{array}$ & $\begin{array}{l}0.000224^{* * *} \\
(0.0000537)\end{array}$ & $\begin{array}{l}0.000461^{* * *} \\
(0.0000995)\end{array}$ & $\begin{array}{l}0.000227^{* * *} \\
(0.0000543)\end{array}$ & $\begin{array}{l}0.000222^{* * *} \\
(0.0000555)\end{array}$ \\
\hline Median Rent & $\begin{array}{c}0.00000919^{* * *} \\
(0.00000151)\end{array}$ & $\begin{array}{c}0.00000812^{* * *} \\
(0.00000139)\end{array}$ & $\begin{array}{c}0.00000801^{* * *} \\
(0.00000138)\end{array}$ & $\begin{array}{c}0.00000808^{* * *} \\
(0.00000141)\end{array}$ & $\begin{array}{c}0.00000805^{* * *} \\
(0.00000136)\end{array}$ \\
\hline Total Population & $\begin{array}{l}-0.00124^{* * *} \\
(0.000425)\end{array}$ & $\begin{array}{l}-0.00136^{* * *} \\
(0.000385)\end{array}$ & $\begin{array}{l}-0.00145^{* * *} \\
(0.000424)\end{array}$ & $\begin{array}{l}-0.00150^{* * *} \\
(0.000408)\end{array}$ & $\begin{array}{l}-0.00137^{* * *} \\
(0.000391)\end{array}$ \\
\hline Percent White & $\begin{array}{c}0.0000210 \\
(0.0000231)\end{array}$ & $\begin{array}{c}0.0000317 \\
(0.0000203)\end{array}$ & $\begin{array}{c}0.0000171 \\
(0.0000239)\end{array}$ & $\begin{array}{c}0.0000218 \\
(0.0000232)\end{array}$ & $\begin{array}{l}-0.0000139 \\
(0.0000487)\end{array}$ \\
\hline Percent Black & $\begin{array}{l}0.000473^{* * *} \\
(0.0000956)\end{array}$ & $\begin{array}{l}0.000477^{* * *} \\
(0.0000868)\end{array}$ & $\begin{array}{l}0.000468^{* * *} \\
(0.0000842)\end{array}$ & $\begin{array}{l}0.000474^{* * *} \\
(0.0000867)\end{array}$ & $\begin{array}{l}0.000463^{* * *} \\
(0.0000881)\end{array}$ \\
\hline Percent Asian & $\begin{array}{l}0.000660^{* *} \\
(0.000276)\end{array}$ & $\begin{array}{l}0.000690^{* * *} \\
(0.000262)\end{array}$ & $\begin{array}{l}0.000756^{* * *} \\
(0.000260)\end{array}$ & $\begin{array}{l}0.000777^{* * *} \\
(0.000270)\end{array}$ & $\begin{array}{l}0.000652^{* *} \\
(0.000270)\end{array}$ \\
\hline Attain*(Pov Rate) & & & $\begin{array}{c}-0.000331^{* * *} \\
(0.000107)\end{array}$ & & \\
\hline NO2 Zscore*(Pov Rate) & & & $\begin{array}{c}0.000576^{* * *} \\
(0.000182)\end{array}$ & & \\
\hline Attain*NO2 Zscore*(Pov Rate) & & & $\begin{array}{c}-0.000495^{* * *} \\
(0.000172)\end{array}$ & & \\
\hline Attain*(Med Inc) & & & & $\begin{array}{c}0.000124^{* *} \\
(0.0000516)\end{array}$ & \\
\hline NO2 Zscore*(Med Inc) & & & & $\begin{array}{c}-0.0000891^{* *} \\
(0.0000392)\end{array}$ & \\
\hline Attain*NO2 Zscore*(Med Inc) & & & & $\begin{array}{l}0.0000827^{* *} \\
(0.0000417)\end{array}$ & \\
\hline Attain*(Pct White) & & & & & $\begin{array}{c}0.0000594 \\
(0.0000517)\end{array}$ \\
\hline NO2 Zscore*(Pct White) & & & & & $\begin{array}{l}-0.0000573 \\
(0.0000436)\end{array}$ \\
\hline Attain*NO2 Zscore*(Pct White) & & & & & $\begin{array}{l}0.0000570 \\
(0.0000438)\end{array}$ \\
\hline Observations & 132156 & 132156 & 132156 & 132156 & 132156 \\
\hline
\end{tabular}

Standard errors in parentheses

${ }^{*} p<0.10,{ }^{* *} p<0.05,{ }^{* * *} p<0.01$ 


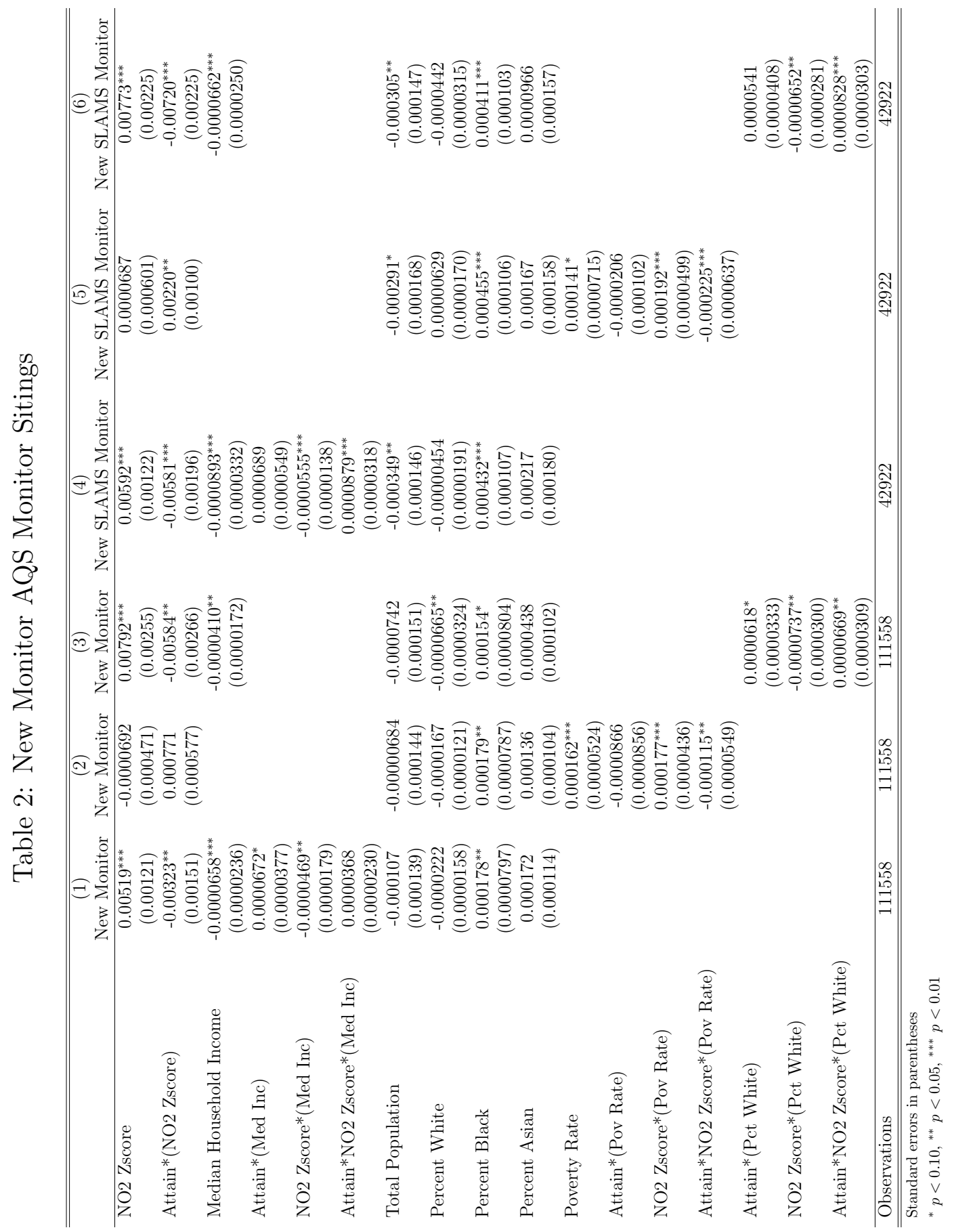

